\title{
Ex vivo evaluation of the effects of several root canal preparation techniques and irrigation regimens on a mixed microbial infection
}

\author{
V. C. Nakamura ${ }^{1}$, S. Cai $^{2}$, G. T. M. Candeiro ${ }^{1}$, P. H. Ferrari ${ }^{1}$, C. L. Caldeira ${ }^{1} \&$ G. Gavini ${ }^{1}$ \\ ${ }^{1}$ Department of Restorative Dentistry, Dental School; and ${ }^{2}$ Department of Microbiology, Institute of Biomedical Sciences, \\ University of São Paulo, São Paulo, Brazil
}

\begin{abstract}
Nakamura VC, Cai S, Candeiro GTM, Ferrari PH, Caldeira CL, Gavini G. Ex vivo evaluation of the effects of several root canal preparation techniques and irrigation regimens on a mixed microbial infection. International Endodontic Journal, 46, 217-224, 2013.
\end{abstract}

\begin{abstract}
Aim To assess the ex vivo effectiveness of the alternated use of $1 \% \mathrm{NaOCl}$ and $15 \%$ citric acid in association with two instrumentation techniques for the disinfection of root canals infected with Enterococcus faecalis and Candida albicans.

Methodology Eighty human mandibular premolars with straight, oval root canals standardized to $15 \mathrm{~mm}$ in length were infected with a mixed culture of $E$. faecalis and C. albicans for 28 days. Five other teeth were used as controls and were neither contaminated nor instrumented. Specimens were divided into two groups $(n=40)$, according to whether the canal preparation technique used manual (K-type) or rotary (Protaper Universal) instruments. These groups were further divided into four subgroups $(n=10)$ according to the irrigation solution used: saline, $1 \% \mathrm{NaOCl}, 1 \% \mathrm{NaOCl}$ with alternated use of $15 \%$ citric acid and 5.25\% $\mathrm{NaOCl}$. Root canals were prepared with a crown-down
\end{abstract}

technique until a size $50 \mathrm{~K}$-file or with rotary preparation until an F5 instrument. Microbiological sampling was performed before (S1) and after (S2) the chemomechanical preparation, using sterile paper points. The specimens were split, and $0.02 \mathrm{~g}$ of dentine chips was collected from the root thirds to verify the presence of microorganisms in root canal walls.

Results Saline and $1 \% \mathrm{NaOCl}$ were less effective in reducing microorganisms compared with $1 \% \mathrm{NaOCl}$ with alternated use of $15 \%$ citric acid or $5.25 \% \mathrm{NaOCl}$ alone $(P<0.05)$. Both manual and rotary preparations significantly reduced microorganisms regardless of the irrigation solution used $(P<0.05)$. However, there was no significant difference between the canal preparation techniques $(P>0.05)$.

Conclusions Irrigation with $5.25 \% \mathrm{NaOCl}$ and $1 \%$ $\mathrm{NaOCl}$ alternated with $15 \%$ citric acid reduced microorganisms in infected root canals significantly more than saline and $1 \% \mathrm{NaOCl}$.

Keywords: chemomechanical preparation, endodontic irrigants, manual instrumentation, root canal disinfection, rotary instrumentation.

Received 10 January 2012; accepted 25 June 2012

\section{Introduction}

Bacteria and their by-products are the primary aetiological agents of pulp and periapical diseases. During

Correspondence: Vitor C. Nakamura, Departamento de Dentística, Faculdade de Odontologia da USP, Av. Prof. Lineu Prestes, 2227, Cidade Universitária, São Paulo, SP, CEP. 05508-000 Brazil (e-mail: vcnakamura@usp.br). root canal treatment, most of these microorganisms are eliminated by the chemomechanical preparation of the root canal, which is performed using endodontic instruments and irrigants (Rôças \& Siqueira 2010). However, some microorganisms persist within the root canal system, making the outcome unpredictable.

Enterococcus faecalis is a Gram-positive anaerobic facultative coccus that has been widely studied in 
endodontics because of its high prevalence in situations of persistent apical periodontitis (Stuart et al. 2006). This microorganism can form biofilms even in situations in which nutrients are scarce (George et al. 2005). E. faecalis is known to penetrate deeply into dentine, making its complete elimination difficult (Chivatxaranukul et al. 2008). In addition, it can survive in high-pH environments without interacting with other microorganisms (Stuart et al. 2006). Along with bacteria, yeasts can also be present in cases of persistent apical periodontitis (Siqueira et al. 2002). Despite being larger than bacteria, yeasts such as Candida albicans can colonize the dentinal tubules to depths of approximately $150 \mu \mathrm{m}$ (Sen et al. 1995). In addition, the ability of this yeast to coexist with other microorganisms is a factor that can significantly increase their survival within the root canal (Ferrari et al. 2005).

Several techniques have been proposed to eliminate microorganisms from root canals. Rotary instrumentation has become widely adopted because its easy and rapid action promotes more uniform root preparations compared with manual files. Nevertheless, the use of irrigants is still required to aid in microbial elimination from the lumen and within dentinal tubules (Berber et al. 2006). In addition, the alternating use of decalcifying and antimicrobial irrigants, such as EDTA and $\mathrm{NaOCl}$, are employed during instrumentation to achieve better disinfection (Soares et al. 2010). Citric acid is an option to remove the smear layer (Zehnder 2006, Prado et al. 2011) and shows appropriate cytotoxicity (Malheiros et al. 2005, Amaral et al. 2007) and antibacterial activity against E. faecalis (Krause et al. 2007, AriasMoliz et al. 2008). However, there are no studies evaluating the use of $1 \% \mathrm{NaOCl}$ with the alternating use of $15 \%$ citric acid on the disinfection of root canals.

Therefore, the aim of this study was to assess the disinfection provided by manual instrumentation using K-type files (Dentsply Maillefer, Ballaigues, Switzerland) and rotary instrumentation (Protaper Universal; Dentsply Maillefer) in root canals infected with E. faecalis and C. albicans in mixed culture. Additionally, the antimicrobial effectiveness of saline, $1 \% \mathrm{NaOCl}, 1 \% \mathrm{NaOCl}$ with alternated use of $15 \%$ citric acid and $5.25 \% \mathrm{NaOCl}$ irrigation solutions was also examined. The null hypothesis was that the disinfection of oval root canals was not affected by the preparation techniques employed nor by the irrigants utilized.

\section{Materials and methods}

\section{Specimen preparation}

In total, 85 human mandibular premolars with a single root canal without internal resorption, calcifications or root dilacerations and with no other anatomical or pathological alterations were selected. The specimens were stored in saline for a minimum period of 7 days for hydration. The crowns were sectioned with diamond discs (KG Sorensen, São Paulo, SP, Brazil) to standardize the root length to $15 \mathrm{~mm}$. Root canals were enlarged using a size $25 \mathrm{~K}$-file (Dentsply Maillefer) and saline until the instrument tip was visualized at the apical foramen.

Transverse grooves that were $0.5 \mathrm{~mm}$ in depth were made 5.0 and $10.0 \mathrm{~mm}$ from the apex of each tooth using a 0.2-mm-thick diamond disc for subsequent specimen cleavage. Specimens were then immersed in an ultrasonic bath of 17\% EDTA-T (Fórmula e Ação Pharmaceutical Manipulation Labs, São Paulo, SP, Brazil) for $3 \mathrm{~min}$, followed by immersion in $5.25 \% \mathrm{NaOCl}$ (Fórmula e Ação Laboratórios de Manipulação, São Paulo, SP, Brazil) for 5 min. Finally, specimens were immersed in distilled water for $3 \mathrm{~min}$. The roots were dried and then covered with two layers of red nail polish, including the apical foramen.

After $24 \mathrm{~h}$, the teeth were inserted individually into $1.5 \mathrm{~mL}$ polypropylene tubes (CRAL Ltda, São Paulo, SP, Brazil) and autoclaved at $121{ }^{\circ} \mathrm{C}$ for $20 \mathrm{~min}$. The control group consisted of five teeth that were neither contaminated nor instrumented to demonstrate specimen sterility.

\section{Microorganism inoculum preparation}

The inoculum was prepared from $50 \mu \mathrm{L}$ of E. faecalis strain (ATCC 29212) and a clinical isolate of C. albicans; each microorganism was inoculated into $50 \mathrm{~mL}$ of tryptic soy broth (TSB) (Difco Labs, Detroit, MI, USA) and cultured under aerobic conditions at $37{ }^{\circ} \mathrm{C}$ for $24 \mathrm{~h}$. The density of each inoculum was calibrated until the turbidity reached level 4 on the McFarland scale, which corresponded to $1.2 \times 10^{9}$ colony-forming units (CFU) per $\mathrm{mL}$. Inocula were then mixed in equal proportions and agitated.

\section{Specimen contamination}

The root canals were inoculated and incubated in aerobic conditions at $37^{\circ} \mathrm{C}$ for 28 days. The culture 
medium was renewed every 2 days. After the incubation period, the root canals were filled with sterile peptone water, and preoperative samples (S1) were collected using three size 20 sterile paper points (Dentsply Maillefer, Petrópolis, Brazil). Each paper point was held in the specimen at working length for $1 \mathrm{~min}$ and then stored in polypropylene tubes containing $1 \mathrm{~mL}$ of sterile peptone water. Next, 10-fold serial dilutions were performed. To confirm the contamination of the specimens, $50-\mu \mathrm{L}$ aliquots were plated on Sabouraud dextrose agar and M-enterococcus agar (Difco Labs). After $48 \mathrm{~h}$ of incubation at $37^{\circ} \mathrm{C}$, microbial growth was recorded. The purity of the cultures was confirmed using Gram staining and colony morphology.

\section{Experimental endodontic procedures}

In total, 80 specimens were divided into two groups ( $n=40$ ) according to chemomechanical preparation technique: manual instrumentation using K-files (Dentsply Maillefer) or rotary instrumentation using Protaper Universal files (Dentsply Maillefer). Each group was further divided into four subgroups $(n=10)$ according to the irrigant used: saline, $1 \%$ $\mathrm{NaOCl}, 1 \% \mathrm{NaOCl}$ with alternated use of $15 \%$ citric acid or $5.25 \% \mathrm{NaOCl}$. The working length was $14 \mathrm{~mm}$ for all specimens.

In canals that were prepared using the crowndown technique, the cervical and middle third were enlarged with size 3 and size 2 Gates-Glidden drills, whereas the apical preparations were performed with a filing motion at the working length, starting with size $30 \mathrm{~K}$-files and working up to size $50 \mathrm{~K}$-files. In teeth that were prepared using the rotary technique, Protaper Universal files (Dentsply Maillefer) were used at $350 \mathrm{rpm}$ and $2 \mathrm{~N}$ per $\mathrm{cm}$ of torque. First, a shaping file 1 (S1) was applied to the canal walls to enlarge the cervical and mid-thirds. Next, S2, F1, F2, F3, F4 and F5 instruments were manipulated in the same way throughout the working length. All instruments were autoclaved at $121{ }^{\circ} \mathrm{C}$ for $20 \mathrm{~min}$ prior to use.

In the subgroups rinsed with saline, $1 \% \mathrm{NaOCl}$ and $5.25 \% \mathrm{NaOCl}, 2 \mathrm{~mL}$ of the irrigation solution was renewed after use of each instrument. In these subgroups, a final rinse was performed using $10 \mathrm{~mL}$ of the respective solution after specimen preparation was complete. The total volume used in instrumentation was standardized to $22 \mathrm{~mL}$. In subgroups irrigated with $1 \% \mathrm{NaOCl}$ with alternated use of $15 \%$ citric acid, $1 \mathrm{~mL}$ of each irrigation solution was employed each time the instrument was replaced; for the final irrigation, $5 \mathrm{~mL}$ of each solution was used. To standardize the irrigation procedure, a peristaltic pump (VK Driller LTDA, São Paulo, Brazil) and a 30-G irrigation needle (Ultradent Products Inc., South Jordan, UT, USA) were used with a constant flow of $5 \mathrm{~mL}$ per min. At the end of each preparation, $\mathrm{NaOCl}$ solutions were buffered with $2 \mathrm{~mL}$ of a sterile solution of $5 \%$ sodium thiosulfate that was held within the root canal for $3 \mathrm{~min}$. Subsequently, the root canals were filled again with sterile peptone water, and postoperative samples (S2) were collected with three size 20 sterile paper cones (Dentsply Maillefer); each paper cone was held inside the root canal for $1 \mathrm{~min}$.

\section{Dentine analysis}

After postoperative canal sampling, the specimens were sectioned in thirds, and 0.02-g samples of dentine were collected from the apical, medium and coronal thirds of each root canal to test for the presence of microorganisms in the tubules. A sterile diamond No.3139 conical bur (Medical Burs Ind, São Paulo, Brazil) was used at $150 \mathrm{rpm}$ without irrigation. Dentine chips were placed into polypropylene tubes containing $1 \mathrm{~mL}$ of sterile peptone water. A digital precision balance (Mettler-Toledo International Inc., São Paulo, Brazil) was used to standardize the weight of the dentine collected. Next, 10-fold serial dilutions were performed. To quantify the microbial growth, $100-\mu \mathrm{L}$ aliquots were plated on M-enterococcus agar (Difco Labs) and Sabouraud dextrose agar in triplicate. The plates were incubated at $37{ }^{\circ} \mathrm{C}$ for $48 \mathrm{~h}$; CFU counts were then performed.

Data were statistically assessed using the MannWhitney $U$-test at significance level of 5\%; all analyses were performed using SPSS 15.0 software (SPSS Inc., Chicago, IL, USA).

\section{Results}

In the dentine chip samples, saline and $1 \% \mathrm{NaOCl}$ irrigation solutions were significantly less efficient in reducing the number of microorganisms (Table 2) compared with $1 \% \mathrm{NaOCl}$ with alternated use of $15 \%$ citric acid and 5.25\% NaOCl $(P=0.00002)$.

Regarding the root canal preparation techniques, both manual (K-files) and rotary (Protaper Universal files) instrumentation significantly reduced the numbers of E. faecalis and C. albicans organisms present in the root canal lumen regardless of the irrigation solution 
Table 1 Means and standard deviations of CFU per mL for Enterococcus faecalis and Candida albicans in the root canal lumen before and after chemomechanical preparation

\begin{tabular}{|c|c|c|c|c|}
\hline \multirow[b]{2}{*}{ Group } & \multirow[b]{2}{*}{$N$} & Before instrumentation (CFU per $\mathrm{mL}$ ) & \multirow{2}{*}{$\frac{\text { After instrumentation (CFU per } \mathrm{mL} \text { ) }}{\text { Mean } \pm \mathrm{SD}}$} & \multirow{2}{*}{$\frac{\text { Percent reduction }}{\text { Mean } \pm \mathrm{SD}}$} \\
\hline & & Mean \pm SD & & \\
\hline \multicolumn{5}{|c|}{ E. faecalis reduction before and after instrumentation } \\
\hline \multicolumn{5}{|l|}{ Manual (K File) } \\
\hline Saline & 10 & $3.68 \times 10^{8} \pm 1.19 \times 10^{8}$ & $4.97 \times 10^{3} \pm 4.13 \times 10^{3}$ & 99.99 \\
\hline $\mathrm{NaOCl} 1 \%$ & 10 & $3.36 \times 10^{8} \pm 1.29 \times 10^{8}$ & $1.8 \times 10^{2} \pm 1.73 \times 10^{2}$ & $99.99 \pm 0.01$ \\
\hline $\mathrm{NaOCl} 1 \%+\mathrm{CA} 15 \%$ & 10 & $3.18 \times 10^{8} \pm 1.45 \times 10^{8}$ & $1.1 \times 10^{2} \pm 98.51$ & $99.99 \pm 0.01$ \\
\hline $\mathrm{NaOCl} 5.25 \%$ & 10 & $3.36 \times 10^{8} \pm 1.42 \times 10^{8}$ & 0 & 100 \\
\hline \multicolumn{5}{|l|}{ Rotary (ProTaper) } \\
\hline Saline & 10 & $3.06 \times 10^{8} \pm 1.27 \times 10^{8}$ & $5.4 \times 10^{3} \pm 4.07 \times 10^{3}$ & 99.99 \\
\hline $\mathrm{NaOCl} 1 \%$ & 10 & $3.52 \times 10^{8} \pm 1.56 \times 10^{8}$ & $1.67 \times 10^{2} \pm 2.24 \times 10^{2}$ & $99.99 \pm 0.01$ \\
\hline $\mathrm{NaOCI} 1 \%+\mathrm{CA} 15 \%$ & 10 & $3.42 \times 10^{8} \pm 1.2 \times 10^{8}$ & $1.02 \times 10^{2} \pm 1.05 \times 10^{2}$ & $99.99 \pm 0.01$ \\
\hline $\mathrm{NaOCl} 5.25 \%$ & 10 & $3.59 \times 10^{8} \pm 1.07 \times 10^{8}$ & 0 & 100 \\
\hline \multicolumn{5}{|c|}{ C. albicans reduction before and after instrumentation } \\
\hline \multicolumn{5}{|l|}{ Manual (K File) } \\
\hline Saline & 10 & $7.48 \times 10^{4} \pm 1.04 \times 10^{4}$ & $7.6 \times 10^{2} \pm 1.5 \times 10^{2}$ & $98.97 \pm 0.21$ \\
\hline $\mathrm{NaOCl} 1 \%$ & 10 & $6.6 \times 10^{4} \pm 1.8 \times 10^{4}$ & $1 \times 10^{2} \pm 1.15 \times 10^{2}$ & $99.87 \pm 0.14$ \\
\hline $\mathrm{NaOCl} 1 \%+\mathrm{CA} 15 \%$ & 10 & $6.65 \times 10^{4} \pm 2.24 \times 10^{4}$ & $51.67 \pm 65$ & $99.94 \pm 0.08$ \\
\hline $\mathrm{NaOCl} 5.25 \%$ & 10 & $6.4 \times 10^{4} \pm 2.19 \times 10^{4}$ & 0 & 100 \\
\hline \multicolumn{5}{|l|}{ Rotary (ProTaper) } \\
\hline Saline & 10 & $6.58 \times 10^{4} \pm 2.1 \times 10^{4}$ & $7.47 \times 10^{2} \pm 1.71 \times 10^{2}$ & $98.72 \pm 0.72$ \\
\hline $\mathrm{NaOCl} 1 \%$ & 10 & $6.71 \times 10^{4} \pm 2.67 \times 10^{4}$ & $99 \pm 99$ & $99.89 \pm 0.11$ \\
\hline $\mathrm{NaOCl} 1 \%+\mathrm{CA} 15 \%$ & 10 & $6.87 \times 10^{4} \pm 1.98 \times 10^{4}$ & $45 \pm 57.76$ & $99.95 \pm 0.06$ \\
\hline $\mathrm{NaOCl} 5.25 \%$ & 10 & $6.72 \times 10^{4} \pm 1.91 \times 10^{4}$ & $3.33 \pm 7.03$ & $100 \pm 0.01$ \\
\hline
\end{tabular}

CA, citric acid.

used (Table 1). There was no significant difference between these techniques $(P>0.05)$. For the dentine chip samples, the Mann-Whitney $U$-test revealed no statistically significant differences $(P>0.05)$ between the preparation techniques when samples from the same root third that were treated with the same irrigation solution were compared (Table 2).

The sterile condition of the root canal system prior to contamination with E. faecalis and C. albicans was verified, as no microbial growth was observed in the control group.

\section{Discussion}

The aim of root canal treatment is to restore or maintain the healthy condition of periapical tissues. This goal is achieved through the reduction or elimination of microorganisms within the root canal system. Chemomechanical canal preparation utilizes several instruments, techniques and chemical substances that attempt to promote the ideal conditions to fill the root canal space. Rotary instrumentation represents a viable option to perform canal preparation because it is faster and the final shape is more uniform compared with manual instrumentation. Additionally, several studies have focused on the effectiveness of disinfection utilizing this method (Berber et al. 2006, Singla et al. 2010). In endodontic practice, $\mathrm{NaOCl}$ is the most common chemical substance employed because of its antimicrobial properties and ability to dissolve organic matter (Krause et al. 2007, Siqueira et al. 2007, Retamozo et al. 2010). Thus, the present study assessed the effectiveness of disinfection through manual and rotary instrumentation within the root canal lumen and dentinal tubules contaminated with E. faecalis and $C$. albicans using saline, 5.25\% NaOCl, $1 \%$ $\mathrm{NaOCl}$ and $1 \% \mathrm{NaOCl}$ with alternated use of $15 \%$ citric acid as irrigation solutions.

Regardless of the preparation technique utilized and the irrigation solution employed, microbial populations were reduced by more than $98 \%$. Nevertheless, dentine chip analysis revealed that microorganisms were still present in the dentinal tubules in all groups, consistent with a report from Câmara et al. (2009). These findings emphasize the difficulty of disinfecting within dentine. The target microorganisms in this study were selected based on their levels of virulence and resistance to antimicrobial agents; additionally, their high prevalence in cases of failed root canal treatments was taken into consideration (Siqueira \& Sen 2004, Stuart et al. 2006). 
Table 2 Means and standard deviations of CFU per mL for Enterococcus faecalis and Candida albicans in dentine ships, according to radicular third and preparation technique

\begin{tabular}{|c|c|c|c|c|}
\hline Radicular third & Saline & $1 \% \mathrm{NaOCl}$ & $1 \% \mathrm{NaOCl}+15 \% \mathrm{AC}$ & $5.25 \% \mathrm{NaOCl}$ \\
\hline \multicolumn{5}{|c|}{ E. faecalis collected from dentine ships } \\
\hline \multicolumn{5}{|l|}{ Cervical } \\
\hline Manual & $2.2 \times 10^{3} \pm 1.2 \times 10^{3} \mathrm{a}$ & $156.67 \pm 110.33 b$ & $90.00 \pm 111.44 \mathrm{c}$ & $11.67 \pm 22.30 \mathrm{c}$ \\
\hline Rotary & $2.5 \times 10^{3} \pm 1.3 \times 10^{3} \mathrm{a}$ & $241.67 \pm 227.34 b$ & $63.33 \pm 85.27 c$ & $11.83 \pm 22.34 \mathrm{c}$ \\
\hline \multicolumn{5}{|l|}{ Medium } \\
\hline Manual & $1.8 \times 10^{3} \pm 7.4 \times 10^{2} \mathrm{a}$ & $170.00 \pm 128.33 b$ & $48.33 \pm 58.50 \mathrm{c}$ & $6.67 \pm 11.65 c$ \\
\hline Rotary & $2.2 \times 10^{3} \pm 1.2 \times 10^{3} \mathrm{a}$ & $263.33 \pm 206.50 b$ & $31.67 \pm 44.06 \mathrm{c}$ & $10.00 \pm 14.05 \mathrm{c}$ \\
\hline \multicolumn{5}{|l|}{ Apical } \\
\hline Manual & $1.3 \times 10^{3} \pm 4.2 \times 10^{2} a$ & $51.67 \pm 46.11 \mathrm{~b}$ & $13.33 \pm 42.16 \mathrm{c}$ & $0.00 \pm 0.00 \mathrm{c}$ \\
\hline Rotary & $1.6 \times 10^{3} \pm 6.5 \times 10^{2} a$ & $188.33 \pm 112.28 b$ & $11.67 \pm 17.65 \mathrm{c}$ & $0.00 \pm 0.00 \mathrm{c}$ \\
\hline \multicolumn{5}{|c|}{ C. albicans collected from dentine ships } \\
\hline \multicolumn{5}{|l|}{ Cervical } \\
\hline Manual & $595.00 \pm 132.65 a$ & $103.34 \pm 80.43 b$ & $25.00 \pm 25.15 c$ & $10.00 \pm 14.05 c$ \\
\hline Rotary & $536.67 \pm 114.61 \mathrm{a}$ & $140.00 \pm 79.43 b$ & $25.00 \pm 26.35 c$ & $5.00 \pm 8.05 c$ \\
\hline \multicolumn{5}{|l|}{ Medium } \\
\hline Manual & $571.67 \pm 220.56 a$ & $91.67 \pm 80.60 b$ & $16.67 \pm 19.24 \mathrm{c}$ & $6.67 \pm 11.65 c$ \\
\hline Rotary & $525.00 \pm 116.07 a$ & $100.00 \pm 46.48 b$ & $18.33 \pm 24.15 c$ & $5.00 \pm 8.05 c$ \\
\hline \multicolumn{5}{|l|}{ Apical } \\
\hline Manual & $200.00 \pm 156.35 a$ & $40.00 \pm 53.98 b$ & $10.00 \pm 17.92 \mathrm{c}$ & $0.00 \pm 0.00 \mathrm{c}$ \\
\hline Rotary & $171.67 \pm 92.65 a$ & $43.33 \pm 60.96 b$ & $10.00 \pm 14.05 c$ & $0.00 \pm 0.00 \mathrm{c}$ \\
\hline
\end{tabular}

CA, citric acid.

Similar letters (from a to $\mathrm{c}$ ) indicate absence of statistical difference in horizontal direction (Mann-Whitney $P>0.05$ ).

Enterococcus faecalis has the ability to colonize dentinal tubules and can penetrate into dentinal tubules to a depth of $1000 \mu \mathrm{m}$ in 21 days (Haapasalo \& Ørstavik 1987). In addition to penetrating into the root canal walls, collagen-binding proteins strengthen the binding of E. faecalis to dentine (Kayaoglu et al. 2008). Further, this microorganism can form biofilms within the root canal system that make the complete disinfection of the root canal system difficult (Liu et al. 2010). The other microorganism used in this study was $C$. albicans, a yeast isolated from persistent lesions that has the ability to penetrate dentinal tubules, adhere to dentine (Sen et al. 1995) and form biofilms (Turk et al. 2008). As a dimorphic fungus, C. albicans can easily adapt to environmental variations through hyphal-to-yeast or yeast-to-hyphal transitions whenever needed (Siqueira \& Sen 2004). Additionally, C. albicans can co-aggregate with several endodontic pathogens (Ferrari et al. 2005). In the present study, both species were viable throughout the entire culture period; this result was also observed by Cardoso et al. (2008). Thus, the results obtained in the present study showed that both root canal preparation techniques resulted in similar disinfection conditions when the groups using the same irrigation protocols were compared. These results are consistent with previous findings (Berber et al. 2006).
Both E. faecalis and C. albicans are susceptible to both concentrations of sodium hypochlorite. Amongst the irrigation protocols examined, $1 \% \mathrm{NaOCl}$ was found to be more effective than only saline solution for eliminating both microorganisms. At a 5.25\% concentration, sodium hypochlorite was more effective, resulting in negative cultures from the root canal lumen and the dentine chip samples.

Specimens that were irrigated using $1 \% \mathrm{NaOCl}$ with alternated use of $15 \%$ citric acid exhibited significantly lower numbers of viable microorganisms compared with the groups that used $1 \% \mathrm{NaOCl}$ only. Citric acid is an organic acid with low cytotoxicity (Amaral et al. 2007) and a demineralizing action that can remove smear layer efficiently (Zehnder 2006, Prado et al. 2011). Bystrom \& Sundqvist (1985) and Soares et al. (2010) suggested the alternated use of $5.25 \% \mathrm{NaOCl}$ and $17 \%$ EDTA for preparing root canals. The authors stated that such an association resulted in cleaner dentinal tubules with greater permeability. Similarly, in this study, the increase in dentinal permeability produced during root canal preparation may have allowed the $1 \% \mathrm{NaOCl}$ to penetrate deeper into the dentinal tubules, thus reaching more bacteria and yeast. Further studies should be conducted to validate this hypothesis. However, Zehnder et al. (2005) demonstrated that associating 
sodium hypochlorite with citric acid or EDTA decreases the antimicrobial capacity of sodium hypochlorite significantly. This discrepancy may be related to the fact that these authors mixed the substances rather than alternating their use, as proposed in this study. In fact, citric acid alone can exhibit antimicrobial action against strict and facultative anaerobic microorganisms (Krause et al. 2007, Arias-Moliz et al. 2008). Soares et al. (2010) stated that an association between sodium hypochlorite and a demineralizing chemical solution might promote a more powerful bacterial effect or interfere with the recolonization process. Georgopoulou et al. (1994) observed that citric acid was ineffective in reducing the number of microorganisms attached to biofilms. Therefore, it is more likely that the bacterial reduction observed in the groups that used $1 \% \mathrm{NaOCl}$ alternately with $15 \%$ citric acid occurred as a result of increased dentine permeability rather than the antimicrobial efficacy of the acid itself.

The results obtained in this study demonstrate the greater efficacy of $5.25 \% \mathrm{NaOCl}$ in eliminating E. faecalis and C. albicans compared with other irrigation protocols, regardless of the instrumentation technique used. However, the choice of the most adequate substance for endodontic therapy also depends on others factors that were not considered here, such as biocompatibility. It is well known that increasing the chloride concentration of sodium hypochlorite solutions also increases their cytotoxicity (Amaral et al. 2007). Several case reports on accidents involving this substance have been described in the literature, mainly when $\mathrm{NaOCl}$ was used at concentrations ranging from $2.5 \%$ to $6.15 \%$ (Kleier et al. 2008, Motta et al. 2009).

There were no significant differences between the CFU counts of the two different instrumentation techniques analysed. These data are consistent with other studies previously reported in the literature (Berber et al. 2006, Chuste-Guillot et al. 2006). It should be noted, however, that according to Paqué et al. (2010), only $20.1 \%$ to $40.4 \%$ of the total volume of oval-shaped root canals are touched by endodontic instruments during the chemomechanical preparation. Thus, the disinfection of untreated surfaces is performed only through the action of irrigants, which may explain the lack of difference between the results.

Similar to the results from previous studies, a higher CFU count was found in the cervical third, followed by the middle and apical thirds. These results are mainly because of the greater amount of dentinal tubules in these portions of the root canal system (Souza et al. 2008). Additionally, the CFU count in the apical third after chemomechanical preparation was low. This result might be explained by all of the root canals being enlarged to file size 50, which might increase the efficacy of irrigation (Brunson et al. 2010) and promote better disinfection (Mickel et al. 2007).

Microorganisms were collected with sterile paper points from the root canal system of extracted premolars. This sampling method has limitations because the paper points are only able to detect planktonic bacteria. Moreover, the paper points cannot access irregularities and other regions of the root canal system. Consequently, this approach might fail to harvest viable bacteria in biofilms and in some areas of the root canal system (Siqueira et al. 2010). Thus, diamond conical burs were used at low speed to remove dentine from the root canal walls and dentinal tubules, allowing for a more predictable sampling. Another critical factor to be considered is the limitation of the culture method because only viable and culturable microorganisms could be counted. Additionally, some cells of E. faecalis in biofilms can enter a stationary phase, which makes them undetectable with conventional culture methods (Liu et al. 2010). Thus, the data obtained from CFU counts must be interpreted with caution.

\section{Conclusion}

Both instrumentation techniques employed for chemomechanical preparation substantially reduced the number of viable microbial cells in the root canal lumen and in the inner walls of the dentine. Furthermore, the alternated use of $15 \%$ citric acid and $1 \%$ $\mathrm{NaOCl}$ during chemomechanical preparation enhanced disinfection, yielding results similar to $5.25 \%$ sodium hypochlorite.

\section{Acknowledgements}

This research was supported by FAPESP (09/51734-9).

\section{References}

Amaral KF, Rogero MM, Fock RA, Borelli P, Gavini G (2007) Cytotoxicity analysis of EDTA and citric acid applied on murine resident macrophages culture. International Endodontic Journal 40, 338-43. 
Arias-Moliz MT, Ferrer-Luque CM, Espigares-Rodríguez E, Liébana-Ureña J, Espigares-García M (2008) Bactericidal activity of phosphoric acid, citric acid, and EDTA solutions against Enterococcus faecalis. Oral Surgery Oral Medicine Oral Pathology Oral Radiology and Endodontology 106, 84-9.

Berber VB, Gomes BP, Sena NT et al. (2006) Efficacy of various concentrations of $\mathrm{NaOCl}$ and instrumentation techniques in reducing Enterococcus faecalis within root canals and dentinal tubules. International Endodontic Journal 39, 10-7.

Brunson M, Heilborn C, Johnson DJ, Cohenca N (2010) Effect of apical preparation size and preparation taper on irrigant volume delivered by using negative pressure irrigation system. Journal of Endodontics 36, 721-4.

Bystrom A, Sundqvist G (1985) The antibacterial action of sodium hypochlorite and EDTA in 60 cases of endodontic therapy. International Endodontic Journal 18, 35-40.

Câmara AC, de Albuquerque MM, Aguiar CM, de Barros Correia AC (2009) In vitro antimicrobial activity of $0.5 \%$, $1 \%$, and $2.5 \%$ sodium hypochlorite in root canals instrumented with the ProTaper Universal system. Oral Surgery Oral Medicine Oral Pathology Oral Radiology and Endodontology 108, 55-61.

Cardoso MG, Oliveira LD, Koga-Ito CY, Jorge AOC (2008) Effectiveness of ozonated water on Candida albicans, Enterococcus faecalis, and endotoxins in root canals. Oral Surgery, Oral Medicine, Oral Pathology, Oral Radiology, and Endodontology 105, 85-91.

Chivatxaranukul P, Dashper SG, Messer HH (2008) Dentinal tubule invasion and adherence by Enterococcus faecalis. International Endodontic Journal 41, 873-82.

Chuste-Guillot MP, Badet C, Peli JF, Perez F (2006) Effect of three nickel-titanium rotary file techniques on infected root dentin reduction. Oral Surgery, Oral Medicine, Oral Pathology, Oral Radiology and Endodontology 102, 254-8.

Ferrari PHP, Cai S, Bombana AC (2005) Effect of endodontic procedures on Enterococci, enteric bacteria and yeasts in primary endodontic infections. International Endodontic Journal 38, 372-80.

George S, Kishen A, Song KP (2005) The role of environmental changes on monospecies biofilm formation on root canal wall by Enterococcus faecalis. Journal of Endodontics 31, $867-72$.

Georgopoulou M, Kontakiotis E, Nakou M (1994) Evaluation of the antimicrobial effectiveness of citric acid and sodium hypochlorite on the anaerobic flora of the infected root canal. International Endodontic Journal 27, 139-43.

Haapasalo M, Ørstavik D (1987) In vitro infection and disinfection of dentinal tubules. Journal of Dental Research 66, 1375-9.

Kayaoglu G, Erten H, Ørstavik D (2008) Possible role of the adhesin ace and collagen adherence in conveying resistance to disinfectants on Enterococcus faecalis. Oral Microbiology and Immunology 23, 449-54.

Kleier DJ, Averbach RE, Mehdipour O (2008) The sodium hypochlorite accident: experience of diplomates of the
American Board of Endodontics. Journal of Endodontics 34, 1346-50.

Krause TA, Liewehr FR, Hahn CL (2007) The antimicrobial effect of MTAD, sodium hypochlorite, doxycycline, and citric acid on Enterococcus faecalis. Journal of Endodontics 33, 28-30.

Liu H, Wei X, Ling J, Wang W, Huang X (2010) Biofilm formation capability of Enterococcus faecalis cells in starvation phase and its susceptibility to sodium hypochlorite. Journal of Endodontics 36, 630-5.

Malheiros C, Jaeger MMM, Gavini G (2005) In vitro comparison of the cytotoxicity of citric acid and EDTA. Journal of Endodontics 31, 746-8.

Mickel AK, Chogle S, Liddle J, Huffaker K, Jones JJ (2007) The role of apical size determination and enlargement in the reduction of intracanal bacteria. Journal of Endodontics 33, 21-3.

Motta MV, Chaves-Mendonça MA, Stirton CG, Cardozo HF (2009) Accidental injection with sodium hypochlorite: report of a case. International Endodontic Journal 42, 17582.

Paqué F, Balmer M, Attin T, Peters OA (2010) Preparation of oval-shaped root canals in mandibular molars using nickel-titanium rotary instruments: a micro-computed tomography study. Journal of Endodontics 36, 703-7.

Prado M, Gusman H, Gomes BPFA, Simão RA (2011) Scanning electron microscopic investigation of the effectiveness of phosphoric acid in smear layer removal when compared with EDTA and citric acid. Journal of Endodontics 37, 255-8.

Retamozo B, Shabahang S, Johnson N, Aprecio RM, Torabinejad M (2010) Minimum contact time and concentration of sodium hypochlorite required to eliminate Enterococcus faecalis. Journal of Endodontics 36, 520-3.

Rôças IN, Siqueira JF Jr (2010) Identification of bacteria enduring endodontic treatment procedures by a combined reverse transcriptase-polymerase chain reaction and reverse-capture checkerboard approach. Journal of Endodontics 36, 45-52.

Sen BH, Piskin B, Demirci T (1995) Observation of bacteria and fungi in infected root canals and dentinal tubules by SEM. Endodontic Dental Traumatology 11, 6-9.

Singla M, Aggarwal V, Logani A, Shah N (2010) Comparative evaluation of rotary ProTaper, Profile, and conventional stepback technique on reduction in Enterococcus faecalis colony-forming units and vertical root fracture resistance of root canals. Oral Surgery Oral Medicine Oral Pathology Oral Radiology and Endodontology 109, 105-10.

Siqueira JF Jr, Sen BH (2004) Fungi in endodontic infections. Oral Surgery Oral Medicine Oral Pathology Oral Radiology and Endodontics 97, 632-4.

Siqueira JF Jr, Rôças IN, Lopes HP, Elias CN, Uzeda M (2002) Fungal infection of the radicular dentin. Journal of Endodontics 28, 770-3.

Siqueira JF Jr, Rôças IN, Paiva SS, Guimarães-Pinto T, Magalhães KM, Lima KC (2007) Bacteriologic investiga- 
tion of the effects of sodium hypochlorite and chlorhexidine during the endodontic treatment of teeth with apical periodontitis. Oral Surgery Oral Medicine Oral Pathology Oral Radiology and Endodontology 104, 122-30.

Siqueira JF Jr, Alves FR, Almeida BM, de Oliveira JC, Rôças IN (2010) Ability of chemomechanical preparation with either rotary instruments or self-adjusting file to disinfect oval-shaped root canals. Journal of Endodontics 36, 1860-5.

Soares JA, Roque de Carvalho MA, Cunha Santos SM et al. (2010) Effectiveness of chemomechanical preparation with alternating use of sodium hypochlorite and EDTA in eliminating intracanal Enterococcus faecalis biofilm. Journal of Endodontics 36, 894-8.

Souza EB, Cai S, Simionato MR, Lage-Marques JL (2008) High-power diode laser in the disinfection in depth of the root canal dentin. Oral Surgery Oral Medicine Oral Pathology Oral Radiology and Endodontology 106, 68-72.

Stuart CH, Schwartz SA, Beeson TJ, Owatz CB (2006) Enterococcus faecalis: its role in root canal treatment failure and current concepts in retreatment. Journal of Endodontics 32 , 93-8.

Turk T, Ates M, Sen BH (2008) The effect of treatment of radicular dentin on colonization patterns of $C$. albicans. Oral Surgery Oral Medicine Oral Pathology Oral Radiology and Endodontology 106, 457-62.

Zehnder M (2006) Root canal irrigants. Journal of Endodontics 32, 389-98.

Zehnder M, Schmidlin P, Sener B, Waltimo T (2005) Chelation in root canal therapy reconsidered. Journal of Endodontics 31, 817-20. 